\title{
Avaliação do perfil eritrocitário de jumentos nordestinos (equus asinus) suplementados com hematínico à base de vitaminas, sais minerais e glicose*
}

\section{Evaluation the profile erythrocyte asinines northeastern (equus asinus) supplemented with hematinics a basis of vitamins, minerals and glucose}

\author{
Luã Barbalho de Macedo, ${ }^{* *}$ Muriel Magda Lustosa Pimentel, ${ }^{* * * *}$ Felipe Venceslau Câmara, ${ }^{* * *}$ Mariana Pinheiro, ${ }^{* * *}$ \\ Bruno Alcântara Sampaio Pinto, ${ }^{* * *}$ Rivaldo Bruno Medeiros de Lucena, ${ }^{* * *}$ André Menezes do Vale, ${ }^{* * * *}$ \\ Océlio Pereira Silva, ${ }^{* *}$ Regina Valéria da Cunha Dias ${ }^{* * * * * *}$
}

\begin{abstract}
Resumo
Este trabalho avaliou as alterações causadas pela administração diária de um hematínico à base de vitaminas do complexo B e K, cobre, cobalto, zinco, ferro e glicose no perfil eritrocitário de asininos da raça Nordestina. Para tanto, foram utilizados oito asininos, que durante 35 dias permaneceram estabulados recebendo alimentação balanceada e água à vontade, além do suplemento em questão. Os parâmetros analisados foram hematócrito, número de hemácias, concentração de hemoglobina, volume corpuscular médio, concentração de hemoglobina corpuscular média, como também a observação das células vermelhas, através de esfregaço sanguíneo. O hematócrito, hemácias, concentração de hemoglobina, VCM e CHCM demonstraram aumento significativo após a utilização do composto, porém não foram observadas alterações nas análises dos esfregaços. O suplemento, ao término do experimento, foi capaz de melhorar o perfil eritrocitário dos animais.
\end{abstract}

Palavras-chave: hematínico, eritrograma, asininos.

\begin{abstract}
This study evaluated the changes caused by daily administration a hematinics based $\mathrm{B}$ and $\mathrm{K}$ vitamins, copper, cobalt, zinc, iron and glucose in erythrocyte profile of the Nordestina breed asinine. Thus, we used eight asinine, which remained stabled for 35 days receiving balanced diet and water ad libitum, and the supplement in question. The parameters studied were hematocrit, erythrocyte count, hemoglobin concentration, mean corpuscular volume, mean corpuscular hemoglobin concentration, as well the observation of red cells, through blood smear. The hematocrit, erythrocytes, hemoglobin concentration, MCV, MCHC demonstrated a statistically significant increase after use of the compound, but no changes were observed in analyzes of smears. The supplement, at the end of the experiment, was able to improve the erythrocyte profile of the animals.
\end{abstract}

Keyword: hematinic, erythrogram, asinine.

\section{Introdução}

O eritrograma, parte do hemograma que avalia a série vermelha do sangue, é realizado em quase todos os pacientes com doença de difícil diagnóstico clínico, pois detecta alterações quantitativas e qualitativas das hemácias, sendo útil para avaliação de prognósticos e da eficácia terapêutica de diversas enfermidades, que possam alterar o quadro eritrocitário como, por exemplo, anemia e desidratação (Cowell; Tyler, 2002; Delfino et al., 2012). O estudo do esfregaço sanguíneo fornece informações sobre contagem celular total e grau de maturação eritrocitária, além de possibilitar a detecção de hemoparasitas (Cowell; Tyler, 2002; Silva, 2011).

A anemia é um dos principais achados encontrados na clínica veterinária, corresponde à redução do número de hemácias circulantes. Dentre as várias causas de anemia, está a falta de componentes essenciais para síntese de hemácias e hemoglobina, como o ferro, vitaminas do complexo B e cobalto (Lee et al., 1974; Ribeiro, 2005; Souza; Elias, 2006).

Entre os tratamentos utilizados para reverter alterações hematológicas da anemia, a utilização de hematínicos recebe grande destaque nas prescrições veterinárias (Rêgo et al., 2011), pois estas substâncias são capazes de melhorar o desempenho físico do animal, além de auxiliar na reposição de células vermelhas, pois contém vitaminas do complexo $B$ e $\mathrm{K}$, oligominerais e glicose em concentrações ideais para desempenharem essas funções (Ribeiro, 2005).

No entanto, não existem relatos na literatura que comprovem a eficiência deste grupo de medicamentos em asininos para

${ }^{*}$ Recebido em 12 de dezembro de 2013 e aceito em 2 de abril de 2014.

**Médico-veterinário, Autônomo, Avenida Francisco Mota,572, Costa e Silva, Mossoró, RN. E-mail: luanb_macedo@hotmail.com.

${ }^{* \star *}$ Curso de Graduação em Medicina Veterinária.

****Médico-veterinário Mestrando na área de Produção Animal na UFERSA. Avenida Francisco Mota,572, Costa e Silva, Mossoró, RN.

${ }^{* * * * *}$ Farmacéutico e Bioquímico do Hospital Veterinário da UFERSA. Avenida Francisco Mota,572, Costa e Silva, Mossoró, RN.

${ }^{* * * * * *}$ Médico-veterinário, Dra. Área de Clínica de Equídeos, Departamento de Ciência Animal, UFERSA. Avenida Francisco Mota,572, Costa e Silva, Mossoró, RN. 
tratamento de anemia, sendo necessários mais estudos a respeito do tema. Assim, o presente estudo teve como objetivo avaliar o efeito da administração diária de um hematínico sobre o perfil eritrocitário em asininos da raça Nordestina.

\section{Materiais e métodos}

O presente trabalho foi aprovado pela comissão de ética do departamento de Ciências Animais da Universidade Federal Rural do Semiárido (DCAN- UFERSA) (Parecer 58/2012). Os procedimentos foram realizados de acordo com as especificações da Comissão de Ética no Uso Animal da UFERSA, o Código de Ética Profissional de Medicina Veterinária, os princípios éticos para pesquisa com animais estabelecidos pelo Código Brasileiro de Experimentação Animal e a legislação brasileira.

O experimento foi conduzido em piquete, pertencente à Universidade Federal Rural do Semiárido, localizada na cidade de Mossoró, Rio Grande do Norte, no período de maio a junho de 2012.

Foram utilizados oito asininos (Equus asinus) da raça Nordestina, com idade entre 3 e 9 anos, do sexo masculino, com média de peso de $100 \mathrm{~kg}$, devidamente identificados através de marcações no pescoço com algarismos romanos de I a VIII.

Os animais foram previamente estabulados, alimentados duas vezes ao dia, com capim Cameron (Pennisetum purpureum) e água à vontade; receberam também, em dias alternados, concentrado à base de $50 \%$ farelo de milho e $50 \%$ farelo de trigo.

Antes da realização do experimento, foi realizada coleta de fezes diretamente da ampola retal, as amostras foram acondicionadas em sacos plásticos, devidamente identificados e imediatamente encaminhadas ao laboratório de parasitologia da UFERSA, para realização da pesquisa de parasitas gastrointestinais, através da técnica de Gordon; Whitlock, 1939. Os testes foram negativos, indicando ausência de endoparasitas nos animais.

Cada animal foi considerado seu próprio animal controle. Para tanto, na semana zero, na qual não houve administração do suplemento, foi realizada a pesagem dos animais com utilização de fita de peso padronizada para equídeos, passando pelo ponto mais alto da cernelha e verificando na fita o peso do animal. Além disso, coletou-se uma amostra de sangue da veia jugular, onde foi acondicionado em frascos de $5 \mathrm{~mL}$ contendo uma gota de ácido etileno-diamino tetra-acético (EDTA). Posteriormente, os frascos foram encaminhados para o laboratório de Patologia Clínica do Hospital Veterinário da UFERSA, onde foram processadas em analisador hematológico veterinário ( $\mathrm{ABC}$ $\mathrm{VET}^{\circledR}$, Horiba $\mathrm{ABX}$ Diagnostics), utilizando-se um cartão de referência para espécie equina. Os parâmetros hematimétricos avaliados foram hematócrito, número de hemácias, dosagem de hemoglobina, volume corpuscular médio e concentração de hemoglobina corpuscular média. Além da análise dos parâmetros citados anteriormente, foram confeccionadas lâminas para esfregaços sanguíneos. Após secagem ao ar livre, os esfregaços foram devidamente identificados e corados a partir do método de Diff-Quick. Para observação das estruturas foi utilizado o microscópio (Olympus CX41RF) na lente objetiva de 100X, com óleo de imersão, conforme técnica padronizada por Birgel (1982). Foi feita análise dos esfregaços por meio de um observador, verificando alterações na morfologia das células vermelhas (poiquilocitose), no tamanho das células (anisocitose) e na coloração dos eritrócitos (anisocromia). Para tanto, foram atribuídos sinais para definir sua presença e intensidade, classificando-as em ausente $(0)$, discreta $(+)$, moderada $(++)$ e intensa $(+++)$.

Após análise das amostras para caracterização da semana zero, os animais foram suplementados independentemente de seu peso vivo, com $20 \mathrm{~mL}$ de Hemolitan $^{\circledR}$, composto de vitaminas do complexo $\mathrm{B}\left(\mathrm{B}_{1}, \mathrm{~B}_{2}, \mathrm{~B}_{3}, \mathrm{~B}_{5}, \mathrm{~B}_{6}, \mathrm{~B}_{9}\right.$ e $\left.\mathrm{B}_{12}\right)$, vitamina $\mathrm{K}_{3}$, zinco, ferro, cobre, cobalto e glicose, uma vez ao dia, por via oral, em horário fixo pre-estabelecido, durante 35 dias. Foram realizadas semanalmente, durante sete semanas, coletas de sangue para avaliação do perfil eritrocitário e análise dos esfregaços sanguíneos, além da pesagem dos animais, sempre antes da alimentação.

A análise estatística dos dados hematimétricos foi processada através do programa estatístico Minitab Statistical Software $®$, versão 14, utilizando o teste T pareado para comparação entre as semanas. A análise qualitativa das lâminas dos esfregaços foi realizada através do teste do qui-quadrado, utilizando o programa Excel versão 2010, sendo adotados para os dois testes, grau de significância de $5 \%$ e intervalo de confiança (IC) de $95 \%$.

\section{Resultados e discussão}

Os valores do hematócrito dos asininos analisados neste trabalho aumentaram no decorrer das semanas, sendo este aumento significativo, apenas na última semana do experimento, conforme descrito na Tabela 1. Este resultado concorda com o obtido por Islam et al. (2005), que avaliaram a eficácia de duas formulações hematínicas, uma à base de sulfato de cobre e sulfato de cobalto e a outra, uma associação de sulfato de cobre com sulfato de cobalto, juntamente com vitamina $B_{12}$ e sulfato ferroso, em caprinos e ovinos, concluindo que a suplementação dos animais com qualquer uma das formulações alcançou resposta significativamente positiva, sendo que caprinos responderam mais rápido que ovinos. Entretanto, Kirkham (1971) testou 11 formulações de compostos hematínicos em equinos Puro Sangue de corrida, observou que somente uma formulação apresentou aumento significativo no hematócrito, porém o autor não especificou sua composição. Ribeiro (2005), testando hematínico (Hemolitan $®$ ) em potros da raça Crioula não observou diferença significativa na comparação entre grupo tratado e grupo controle. Este fato pode ter ocorrido devido às diferenças entre formulações dos suplementos e/ou dosagens dos mesmos para estas espécies.

Os valores médios da contagem de hemácias aumentaram, alcançando significância somente na sexta semana do experimento, conforme descrito na Tabela 1. Este resultado também foi obtido por Islam et al. (2005), que avaliaram caprinos e ovinos quanto à eficácia de duas formulações hematínicas constituídas de sulfato de cobre e sulfato de cobalto e a outra formulação contendo além destes, vitamina $B_{12}$ e sulfato ferroso, obtendo resposta positiva em ambas as espécies. O cobre, cobalto, ferro e vitamina $B_{12}$ ajudam na formação e maturação das hemácias, promovendo maior contagem total das hemácias, estando esses elementos presentes em ambos os trabalhos, justificando assim a importância da suplementação adequada para as diferentes espécies. Todavia, Ribeiro (2005) e Rêgo et al. (2011) não obtiveram médias do número de hemácias 
significativamente diferentes entre o grupo controle e o grupo tratado em equinos da raça Crioula e ovinos respectivamente; dessa maneira, o uso de hematínicos para essas espécies não provocou alterações significativas no parâmetro citado. Esse fato pode ser atribuído à quantidade administrada, que, quando adequada, promove a recuperação das características hematológicas.

Já a dosagem de hemoglobina obteve aumento significativo nas semanas 3 e 5, como demonstrado na Tabela 1. Estes resultados concordam com o encontrado por Islam et al. (2005), cujos estudos com ovinos e caprinos suplementados com duas formulações diferentes de hematínicos, observaram aumentos gradativos na concentração de hemoglobina nestes animais, havendo sempre significância nestes aumentos, provando assim a eficácia de ambas as suplementações administradas. $O$ cobre, cobalto e ferro são elementos essenciais para a síntese da hemoglobina, quando utilizados em dosagens coerentes para cada espécie, justificando a melhora da concentração de hemoglobina em ambos os trabalhos. Todavia, Ribeiro (2005) e Rêgo et al. (2011) avaliaram a suplementação de hematínicos em equinos da raça Crioula durante 60 dias e em ovinos durante 28 dias, respectivamente, não observando diferenças significativas na concentração de hemoglobina entre grupos controle e tratados. Isso pode indicar uma possível subdosagem na suplementação destes animais, discordando com esta pesquisa, que apresentou significância na concentração de hemoglobina com aproximadamente 30 dias.

As médias do VCM dos animais estudados aumentaram significativamente no decorrer das semanas, conforme observado na Tabela 1. Além disso, o CHCM apresentou aumento significativo apenas na sexta semana do experimento, quando comparado com os valores encontrados na semana zero, conforme demonstrado na Tabela 1, o que concorda com Islam et al. (2005), que analisaram a eficiência da suplementação de duas formulações de hematínicos em ovinos e caprinos, obtendo resposta significativa em VCM apenas para caprinos e CHCM em ambas as espécies. Acredita-se que a suplementação dos animais dessas espécies com o hematínico promoveu a multiplicação e maturação das hemácias, havendo aumento no hematócrito, número de hemácias e dosagem de hemoglobina, que consequentemente causaram aumento no VCM e CHCM.

Nos esfregaços dos asininos avaliados neste trabalho, não foram observadas alterações significativas nas variáveis

\section{Referências}

BIRGEL, Eduardo Harry. Hematologia Clínica veterinária. In: BIRGEL, E. H.; BENESI, F. J. Patologia clínica veterinária. São Paulo: Sociedade Paulista de Medicina Veterinária, 1982. p. 2-34.

COWELL, Rick.; TYLER, Ronald. Diagnostic citology and hematology of the horse. $2^{\text {nd }}$ ed. Misouri: Mousby, 2002.

DELFINO, Luciano. et al. Efeito do estresse calórico sobre eritrograma de ruminantes. Revista agropecuária cientifica no semiárido. v. 8, n. 2, p. 01-07, 2012. analisadas (poiquilocitose, anisocitose e anisocromia). Logo, é possível supor que os animais utilizados nesta pesquisa não apresentavam deficiência de ferro, vitamina B12 e ácido fólico, pois os mesmos eram suplementados com Hemolitan®. Todavia, os valores de referência são baseados em equinos, podendo haver diferenças entre as espécies, sendo necessários maiores estudos em asininos.

Comparando os valores dos parâmetros do eritrograma obtidos na semana controle deste estudo com os valores de referência em asininos citados por Weiss e Wardrop (2010), que encontraram valores de hemoglobina variando de 9,5 a $16,5 \mathrm{~g} /$ $\mathrm{dL}^{-1}$; hemácia de 4,7 a $9,0 \times 10^{6} / \mu \mathrm{L}^{-1}$ e hematócrito de 28 a $47 \%$, foi possível afirmar que os animais utilizados neste experimento encontravam-se anêmicos. Todavia, com a administração do hematínico no decorrer das cinco semanas seguintes, observouse melhora significativa no perfil eritrocitário desses asininos, confirmando a eficácia do produto.

\section{Conclusão}

Com a suplementação do hematínico à base de vitaminas, sais minerais e glicose foi possível observar, através do eritrograma, que houve aumento significativo no hematócrito, dosagem de hemoglobina, contagem de hemácias, volume corpuscular médio e concentração de hemoglobina corpuscular média. Já nos esfregaços sanguíneos não foram observadas alterações no formato das células, porém essas eram consideradas fisiológicas para espécie asinina.

Sendo assim, com resultados obtidos durante o experimento, pode-se concluir que o suplemento Hemolitan ${ }^{\circledR}$, nas condições propostas neste trabalho, foi capaz de melhorar significativamente o perfil eritrocitário de asininos.

Tabela 1: Valores médios e desvio padrão do eritrograma de asininos suplementados com Hemolitan ${ }^{\circledR}$ nas diferentes semanas

\begin{tabular}{ccccccc}
\hline \multicolumn{7}{c}{ Semanas } \\
\hline Parâmetros & $\mathbf{0}$ & $\mathbf{1}$ & $\mathbf{2}$ & $\mathbf{3}$ & $\mathbf{4}$ & $\mathbf{5}$ \\
\hline HT & $24,7 \pm 3,3$ & $23,8 \pm 2,0$ & $25,9 \pm 2,7$ & $25,4 \pm 2,6$ & $25,7 \pm 1,8$ & $26,5 \pm 2,2^{*}$ \\
\hline He & $5,8 \pm 0,6$ & $5,5 \pm 0,4$ & $5,9 \pm 0,5$ & $5,9 \pm 0,5$ & $5,9 \pm 0,3$ & $6,1 \pm 0,4^{*}$ \\
Hb & $6,0 \pm 0,7$ & $5,8 \pm 0,4$ & $6,2 \pm 0,5$ & $6,3 \pm 0,6^{*}$ & $6,2 \pm 0,4$ & $6,5 \pm 0,5^{*}$ \\
VCM & $42,2 \pm 2,0$ & $43,1 \pm 2,0^{*}$ & $43,5 \pm 1,6^{*}$ & $43,0 \pm 2,0^{*}$ & $43,1 \pm 2,0^{*}$ & $43,0 \pm 2,0^{*}$ \\
CHCM & $24,7 \pm 3,3$ & $23,8 \pm 2,0$ & $25,9 \pm 2,7$ & $25,4 \pm 2,6$ & $25,7 \pm 1,8$ & $26,5 \pm 2,2^{*}$ \\
\hline
\end{tabular}

*Significativo $(p<0,05)$; HT - Hematócrito; He - Hemácias; Hb - Hemoglobina; VCM - Volume Médio Corpuscular; CHCM - Concentração de Hemoglobina Corpuscular Média.
GORDON, Hugh McLeod; WHITLOCK, A.V. A new technique for counting nematode eggs in sheep feces. Journal Council Scientific Industry Research Australia, v. 12, p. 50-52, 1939.

ISLAM, R.; RASHID, S.M.H.; RAHMAN, M. Effects of hematinics on body weight and some hematological values in sheep and goats. Internacional Journal Agriculture and Biolology, v. 7, n. 4, 2005.

KIRKHAM, W.W. et al. Hematopoietic responses to hematinics. Journal of the Veterinary Medical Association. n.159, p. 13161319. 1971. 
LEE, J.A. et al. Effect of temperature season on bovine adrenal cortical function, blood cell profile, and milk production. Journal of dairy Science, Champaign, v. 59, n. 1, p. 104-108, 1974.

LOPES, Sonia Terezinha dos Anjos. Manual de Patologia Clínica Veterinária 3. ed. - Santa Maria: UFSM/Departamento de Clínica de Pequenos Animais, 2007, 107 p.

RÊGO, Renato Otaviano et al. Respostas Hematológicas ao uso de hematínicos em ovinos anêmicos. In: XXXVIII Congresso Brasileiro de Veterinária, 2011. Anais... Florianópolis: XXXVIII CONBRAVET, 2011.

RIBEIRO, Marcelo Dellazzana. Parâmetros hematológicos de potros da raça Crioula suplementados com um hematínico. 2005. 52 f. Dissertação (Mestrado) - Universidade Federal de Santa Maria, Santa Maria, RS. 2005.
SILVA, Helena Isabel Soares Borges e. Contribuição para o estudo do hemograma do cavalo puro-sangue lusitano. 2011. 78 f. Dissertação (Mestrado) - Curso de Pós-graduação em Medicina Veterinária, Universidade Lusófona de Humanidades e Tecnologias, 2011.

SOUZA, Maria Helena L.; ELIAS, Decio O. Fundamentos da circulação extra corpórea. 2. ed., 2006. Centro editorial Alfa Rio. Rio de janeiro. Disponivel em: http://perfline.com/livro/index.html. Acessado dia 24 de julho de 2012.

WEISS, Douglas J; WARDROP, K. Jane. Schalm's Veterinary Hematology, 6. ed. Ames (IA): Blackwell Publishing, 2010. 